Portegies, P., De Gans, J., Lange, J., Derix, M., SPEelman, H., BAKKer, M., DANNER, S. \& GOUDSMIt, J. (1989) Declining incidence of AIDS dementia complex after introduction of Zidovudine treatment. British Medical Journal, 299, 819-821.

Schmitt, E., Bigley, J., Mcinnis, R., Logue, P., Evans, R. \& DRUCKER, J. (1988) Neuropsychological outcome of AZT treatment of patients with AIDS and ARC. The New England Journal of Medicine, 319, 1573-1578.
TANNOCK, C. \& Collier, C. (1989) We're Just in Time AIDS, Brain Damage and Psychiatric Hospital Closures: a policy rethink. London: Bow Group.

WHO (1988) Report of the Consultation on the Neuropsychiatric Aspects of HIV Infection. Global Programme on AIDS. WHO.

Approved by Council

June 1990

\section{President's Essay Prize}

The President's Essay Prize will be offered for the first time in 1991, as part of the College's 150th Anniversary celebrations. Depending on the success of this award, consideration will be given to establishing the Prize for future years.

The Prize, value $£ 200$, will be offered for an essay of 2,000-3,000 words. The topic for 1991 is the assessment of the therapeutic effects on psychiatric patients of a pleasant and congenial environment, both in and out of hospital.

Applicants are expected to include a critical review of the current relevant literature and on this to base some original comments and conclusions.
Entry is open to all Members and Associates* of the College, without restrictions as to age or seniority. Entrants should include a brief curriculum vitae and send their submissions to the President, at the College, by 31 January 1991 .

Judges for the Prize will be the President, the Dean and the Chairman of the Public Policy Committee.

*"Members and Associates of the College" means that applications can be received from "registered Members and Fellows of the College" as well as the "registered Affiliates, Honorary Fellows, Corresponding Fellows, Corresponding Associates, Inceptors, New Affiliates and New Associates".

\title{
Senior registrar numbers in general psychiatry and old age psychiatry
}

As a result of the College's submission to the Joint Planning Advisory Committee at the end of last year, the Department of Health has agreed to increase the allocation of senior registrar posts in the above specialties. This increase of 90 posts brings the number of posts allocated to general psychiatry and old age psychiatry as a whole to 480 .

In view of the establishment of old age psychiatry as a separate specialty of psychiatry, the Department of Health has assigned one third of the new total (480) to higher training in old age psychiatry.

In its future assessment of higher training schemes in general and old age psychiatry the Joint Committee on Higher Psychiatric Training will expect sufficient training opportunities in old age psychiatry to be available.

Professor A. C. P. Sims

President

\section{Overseas Doctors' Training Scheme}

The Overseas Doctors' Training Scheme (ODTS) has been in operation for just over a year. During this time we have placed nearly 40 doctors in posts throughout the UK.

The scheme now has a rapidly lengthening waiting list of doctors who have been accepted by the College for sponsorship but for whom no post has yet been identified. We are consequently hoping to expand our list of training offers to accommodate the increasing number of applicants whom we hope to place in post in February 1991.
I would be very grateful to hear from any psychiatric tutors who would like to reserve an SHO or registrar post on their general professional training scheme for an overseas trainee sponsored by the College. Interested tutors should contact me at the College for further information.

I should also like to take this opportunity to thank all tutors and consultants currently involved in the scheme for their help and support in developing the ODTS.

Dr Fiona Caldicott, Dean 